\author{
Military Technical College \\ Kobry Elkobbah, Cairo, \\ Egypt.
}

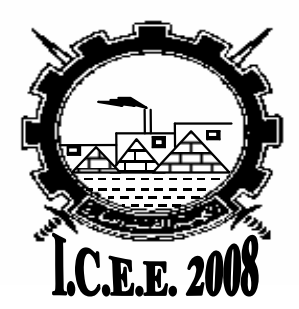

$4^{\text {th }}$ International Conference On Chemical \& Environmental Engineering 27-29 May 2008

\title{
RECRYSTALLIZATION AS A TECHNIQUE FOR LOWERING THE SENSITIVITY OF RDX
}

\author{
Mohamed*, M. K. Mohamed $^{* *}$ H.S. and Saeed*.A.H.
}

\begin{abstract}
RDX is one of the most famous energetic materials. It has excellent properties as a high explosive, energetic additive to rocket and gun propellant and also as a main constituent of the plastic bonded explosives .Its sensitivity to both impact and friction is higher than many of the common used explosives. Safe production and handling need RDX of lower sensitivity. The traditional way of reducing this sensitivity is to add about $5 \%$ of the common paraffin wax. The added wax reduces the specific energy output of this important explosive. Controlled recrystallization could also reduce the sensitivity as it alters its purity, morphology and imperfections. Supersaturation of RDX in acetone could be obtained via cooling, solvent evaporation and also via adding cold water as a third component. The obtained crystals were experimentally characterized and the results were presented and discussed.
\end{abstract}

* Egyptian Armed Forces.

** National Authority for Military production 


\section{INTRODUCTION}

Cyclotrimethylenetrinitramine (RDX) is one of the most important high explosives . Recently, a grade of RDX called Reduced Sensitivity RDX (RS-RDX) has been attracted a lot of attention in the field of insensitive munitions (IM) [1]. RDX sensitivity was traditionally reduced by addition of about $5 \%$ of the paraffin wax [2] RS-RDX can be prepared via a controlled recrystallization [3] . Crystal structure plays a significant role in determining the sensitivity to both the impact and friction. The hot spots are most probably formed at the regions containing significant defects or impurities. The sharp edges, microcracks, dislocations, internal porosity and surface heterogeneities are usually blamed for initiation [4]. The recent studies on the fine recrystallized RDX particles have revealed improvements including reduced shock and impact sensitivity [5]. In this work trails have been made in order to recrystallized the unwaxed RDX.

The particle size, particle shape, surface and internal defects of the recrystallized RDX were detected via optical microscopy, image analysis, and X-Ray diffraction .The sample sensitivity and DSC results are presented and discussed.

\section{EXPERIMENTAL WORK}

\subsection{Set up and procedure}

The apparatus in Fig.1. was employed for recrystallization of the unwaxed RDX which was initially dissolved in acetone at $58^{\circ} \mathrm{C}$ until saturation (about $8 \mathrm{~g}$ RDX per $64 \mathrm{ml}$ acetone). Supersaturation was achieved via three different techniques:

(1) by evaporating about $50 \%$ of the solvent via stopping the refluxing operation .

(2) by cooling the solution to reduce the solubility of RDX in acetone via replacing the heating bath by an ice bath.

(3) by adding cold water as antisolvent to reduce the solubility of RDX in acetone.

The obtained RDX crystals were then aged for 15 minutes with agitation. Finally the crystals were filtered, dried at $60^{\circ} \mathrm{C}$ until constant weight and tested for sensitivity, morphology and defects.

\subsection{The impact test}

The drop weight impact sensitivity test was performed for the unwaxed and the recrystallized RDX samples. These tests were performed with the IKa Maschinebou impact tester, always with a $1 \mathrm{~kg}$ drop weight. Samples of about $0.02 \mathrm{~g}$ of RDX were tested. The results were reported as a relation between the percentage of successful initiations and the corresponding drop height. Successive trails were performed for each drop height. The upper sensitivity limit $(\mathrm{H} 100)$ was used to identify the minimal height (energy) needed to achieve 100\% initiation [6]. Impact energy of dropping weight(IE) at each height was calculated according to the equation:

Where:

$$
\mathrm{IE}=\mathrm{m} \cdot \mathrm{H} \cdot \mathrm{g}
$$

IE ... Impact energy (J).

$\mathrm{m}$... mass of the dropping weight $(\mathrm{kg})$.

H ... drop height $(\mathrm{m})$.

$\mathrm{g}$... acceleration due to gravity $\left(\mathrm{m} / \mathrm{sec}^{2}\right)$ 


\subsection{The friction test}

The Chilworth BAM friction tester was used to determine the sensitivity to friction . The apparatus lever was loaded with different loads at ten different positions. The friction force in Newton for certain load and certain position was obtained from the relevant calibration table. Sensitivity to fiction was determined by spreading about $0.02 \mathrm{~g}$ of the tested sample on the surface of the porcelain plate and in the form of a thin layer. Sample initiation may be observed through sound effects, smoke appearance, or by the characteristic smell of the decomposition products. Six consecutive trials were performed for each load and lever position [7].

\subsection{The scanning electron microscope}

The particle shape and surface state were examined via photographs obtained using a scanning electron microscope (SEM) REMMA-202 this microscope is equipped with X-raymicroanalysis capabilities with accelerating voltage $40 \mathrm{KV}$, resolution $70^{\circ} \mathrm{A}$ and magnification range (10X-200000X).

\subsection{The differential scanning calorimetery}

The thermal stability indicated by the ignition temperature, melting point, $\Delta \mathrm{H}_{\text {Crystallization }}$ and $\Delta \mathrm{H}_{\text {Decompostion }}$ were investigated using a DSC. Using LINSEIS DSC PT10 Platinum series with temperature range from $-150^{\circ} \mathrm{C}$ up to $+700^{\circ} \mathrm{C}$.

Heating/Cooling rates 0.1 up to $50^{\circ} \mathrm{C} / \mathrm{min}$, temperature accuracy $+/-0.2^{\circ} \mathrm{C}$ (substance calibration), and resolution $0.125 \mu \mathrm{W}$.

\section{RESULTS AND DISCUSSION}

Investigation of the collected results for both the unwaxed and recrystallized RDX revealed that the recrystallization of RDX can alert both the sensitivity and the thermal properties of this relatively sensitive high explosive Results of sensitivity tests are given in Table 1.

Table1. Sensitvity to impact and friction for both unwaxed and recrystallized RDX

\begin{tabular}{|c|c|c|c|}
\hline $\begin{array}{c}\text { Sample } \\
\text { code }\end{array}$ & Designation & $\begin{array}{c}\text { Impact } \\
\text { energy } \\
{\left[\mathbf{J}^{*}\right.}\end{array}$ & $\begin{array}{c}\text { Friction } \\
\text { force [N] }\end{array}$ \\
\hline UWAX & Unwaxed & 7.27 & 160.2 \\
\hline EVAP & $\begin{array}{c}\text { Recrystallized via evaporation } \\
\text { about 50\% of the solvent }\end{array}$ & 10 & 200.7 \\
\hline ADD & $\begin{array}{c}\text { Recrystallized via addition of cold water } \\
\text { of the same weight as acetone }\end{array}$ & 12.7 & 180.4 \\
\hline COOLAG & Recrystallized via cooling with agitation & 9.1 & 190.55 \\
\hline
\end{tabular}

*Minimum energy needed for initation by impact

${ }^{* *}$ Minimum force needed for $100 \%$ initation by friction

It is clear that from theses results in that recrstallization can generally reduce the sensitivity of RDX to both friction and impact. These results can be explained 
regarding the expected improvements in the purity and surface homogeneity compared with the unwaxed samples.

The crystals obtained via addition of the cold water as an antisolvent were much more fine and homogenous and consequently less sensitive to both mechanical and thermal stimulii . Fig.2. shows representative SEM photographs for the unwaxed and recrystallized samples. The unwaxed particles were more scattered from the view point of the particle size. They also have numerous pores and surface cracks .On the other hand, the recrystallized particles were almost of polyhedral shape with smooth surfaces ; The particles obtained via evaporation have large crystal size , smooth surface and regular shape ; the particle obtained via cooling with agitation have a very smooth surface.

The internal defects of the tested samples were detected using an optical microscope with refractive index matched fluids. Fig.3. shows some representative optical micrographs. The micrographs relevant to the unwaxed RDX crystals, includes a lot of dark lines corresponding to defects (cavities or a cracks). The samples obtained via evaporation of the solvent (EVAP) include voids and solvent inclusions appearing as a dark points in crystals observed in the dark points. Where as those obtained via cooling with agitation (COOLAG) or via addition of cold water (ADD) do not show any darkness. They can be considered defect free high quality and consequently less sensitive samples.

Results of the DSC investigations are given in Table 2.

It is clear from these results that the crystals are generally stable and evidence was catched indicating occurance of solid phase transformations . were not far from. Thermal analysis data using DSC one of the most important ways that can show if there is crystal phase transition at different temperatures and knowing if the sample has one or more than one crystal phase.

Table 2. Thermal analysis data from DSC

\begin{tabular}{|c|c|c|c|c|}
\hline Sample code & $\begin{array}{c}\mathrm{T} \text { melting } \\
{\left[{ }^{\circ} \mathrm{C}\right]}\end{array}$ & $\begin{array}{l}\text { T Ignition } \\
{\left[{ }^{\circ} \mathrm{C}\right]}\end{array}$ & $\begin{array}{c}\Delta \mathrm{H}_{\text {Crystallization }} \\
{[\mathrm{J} / \mathrm{g}]}\end{array}$ & $\begin{array}{c}\Delta \mathrm{H}_{\text {Decompostion }} \\
{[\mathrm{J} / \mathrm{g}]}\end{array}$ \\
\hline UWAX & 205.1 & 244.1 & 104.0941 & -2545.135 \\
\hline EVAP & 206.7 & 243 & 112.9577 & -3489.609 \\
\hline ADD & 206.8 & 243.7 & 103.2519 & -2748.093 \\
\hline COOLAG & 206.4 & 243.6 & 97.8576 & -2556.2 \\
\hline
\end{tabular}

The observed small differences in melting point of the different samples may be due to corresponding minute difference in the purity of crystals. The recorded values were generally very close to melting point of the pure RDX [2] .

\section{CONCLUSION}

Size, shape surface properties and internal defects of the obtained RDX crystals are all affected by the techniques of recrystallizaion. sudden addition of water as antisolvent resulted in nearly pure, defect free, fine and smooth crystals .

Sensitivity of this product to both impact and friction was found minimum comparing 
with the crystals obtained either by cooling or by solvent evaporation .

Purity and thermal properties were found nearly independent on the recrystallization technique. The supersaturation accompyning the addition of water is therefore quite enough for formation of the obtained regular and less sensitive crystals.

\section{REFERNCES}

[1] Shinichi, M., Eiji,Y., Satoshi, S., Yoshimas, S., Tadashi, H., Yukio, Kato R \& D division, NIPPON KOKI CO, "Reduced Sensitivity RDX (RS-RDX): Effects of crystal quality and shape on the shock sensitivity of RS-RDX based PBXN-109 formulation “, LTD. 2-1 Dobu, Nagasaka, Nishigou-mura, Nishishirakawa-gun, Fukushima 961-8686, Japan.

[2] T-Urbanski ,Chemistry and Technology of explosives ,vol.3,(1985).

[3] Kwang,J., Hyoun,S., Jeong,K., "Simulation of T-mixer crystallizer for nano/micro sized particle formation", 1. National Research Laboratory for Crystallization Process \& Engineering, Fine-Chemical Process \& Engineering Center, Korea Research Institute of Chemical Technology, P.O.Box 107, Yusung-Ku, Taejeon 305-343, Republic of Korea.

[4] S.Lecume1,C.Boutry1,C.Spyckerelle2,"STRUCTURE OF NITRAMINES CRYSTAL DEFECTS RELATION WITH SHOCK SENSITIVITY", 1SNPE Matériaux Energétiques, Centre de Recherches du Bouchet, 91710, Vert Le Petit, FRANCE 2EURENCO France, 146 Route d'Avignon, 84706 Sorgues, FRANCE.

[5] Stepanov1, Philip, S., Inga, B., Elkina2, Xuyean, Z., Nikolai, L., Lavrik2 and Lev, N., "Recrystallization of RDX by Rapid Expansion of Supercritical Solutions (RESS)", Victor 1 US Army, RDECOM-ARDEC, Armaments Engineering Technology Center, Picatinny, NJ 07806 USA 2Department of Chemistry and Environmental Science, 2aMaterial Characterization Laboratory, New Jersey Institute of Technology, University Heights, Newark, NJ 07102, USA

[6] MIL-STD-1751A, Method 1012, "Impact Sensitivity Test -ERL(Explosives \&rocket propellant Laboratory)/ IKa Maschinebou Apparatus", December 2007

[7] PHYWE BAM friction apparatus catalogue, Germany, (1999). 


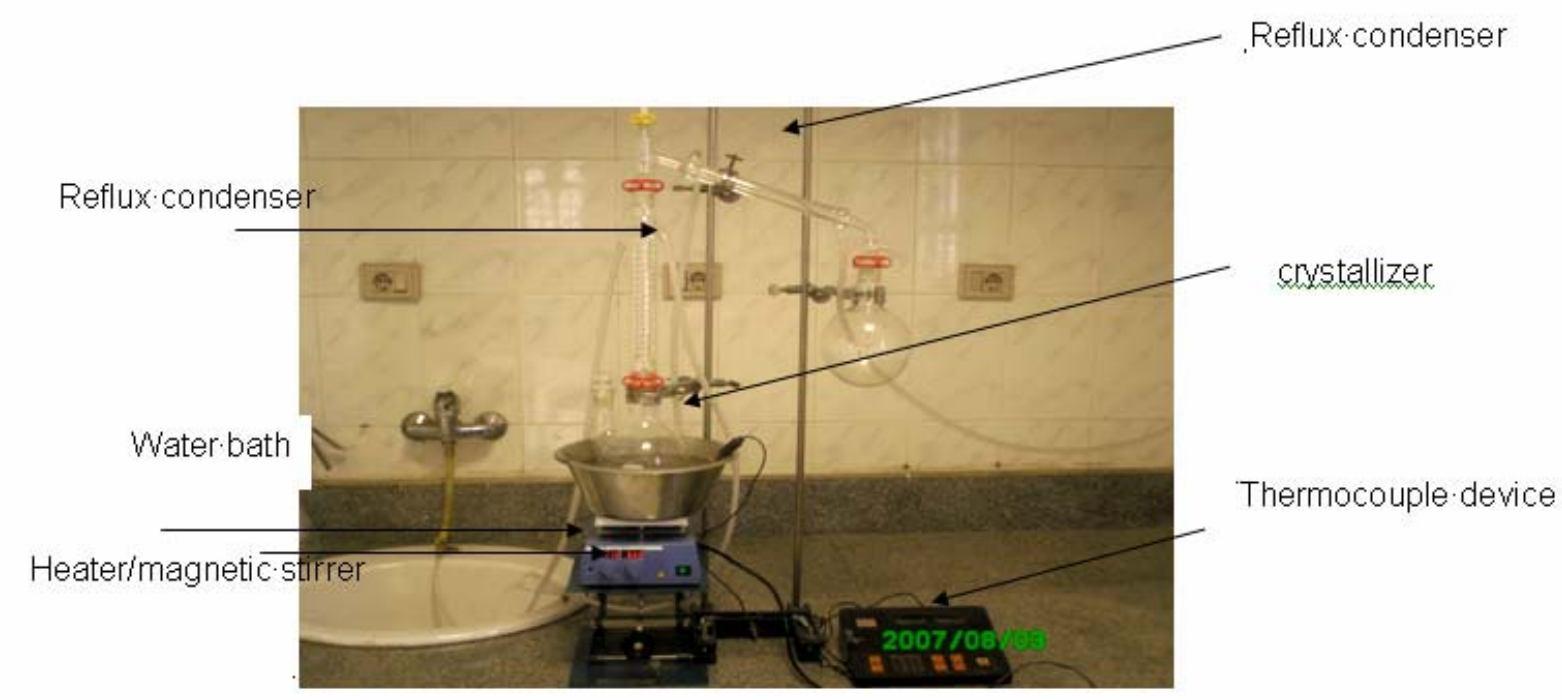

Fig.1. Recrystalliztion set up

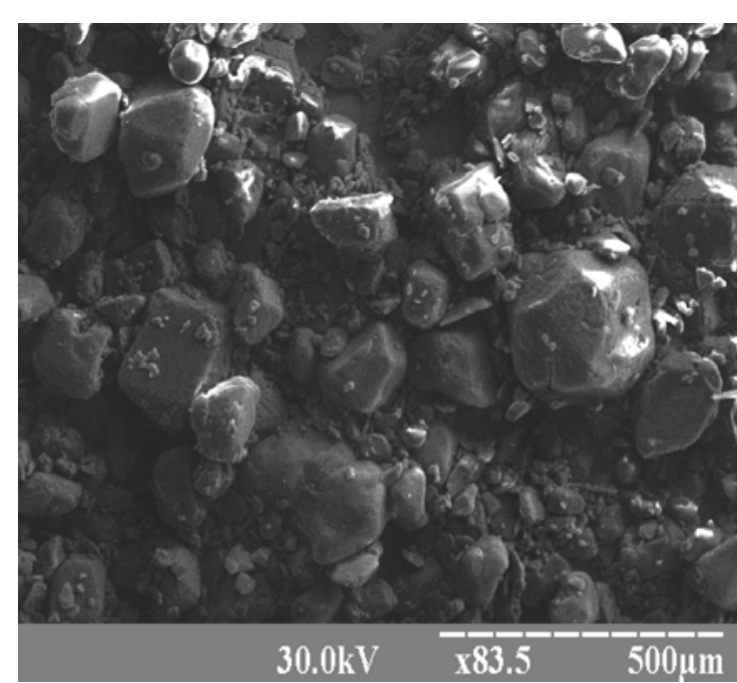

UWAX

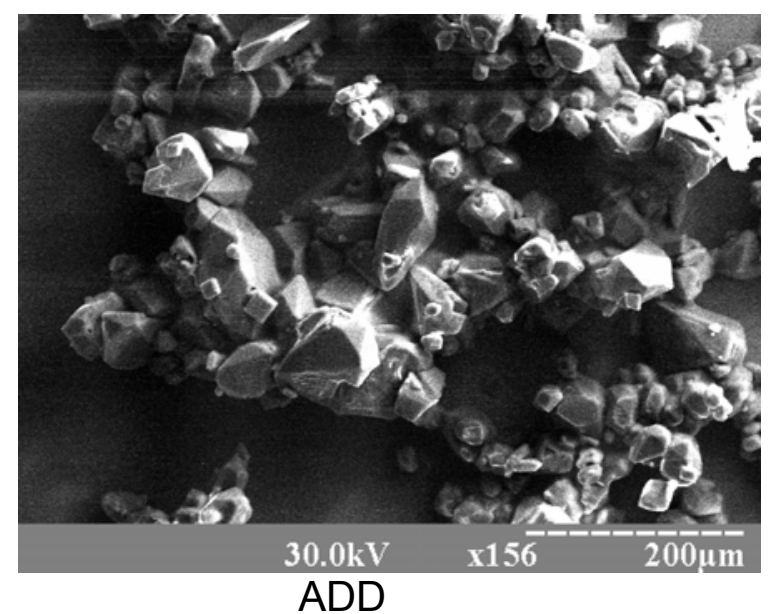

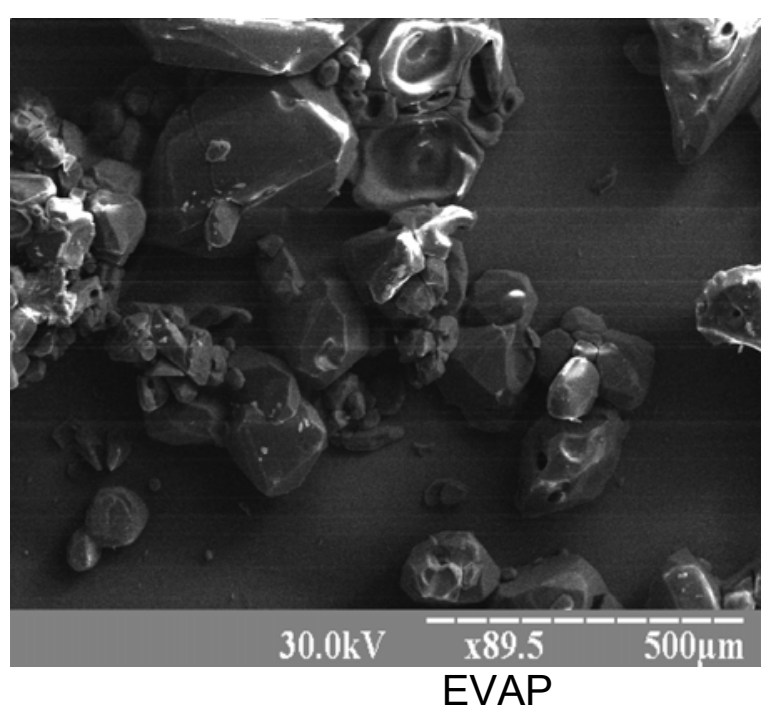

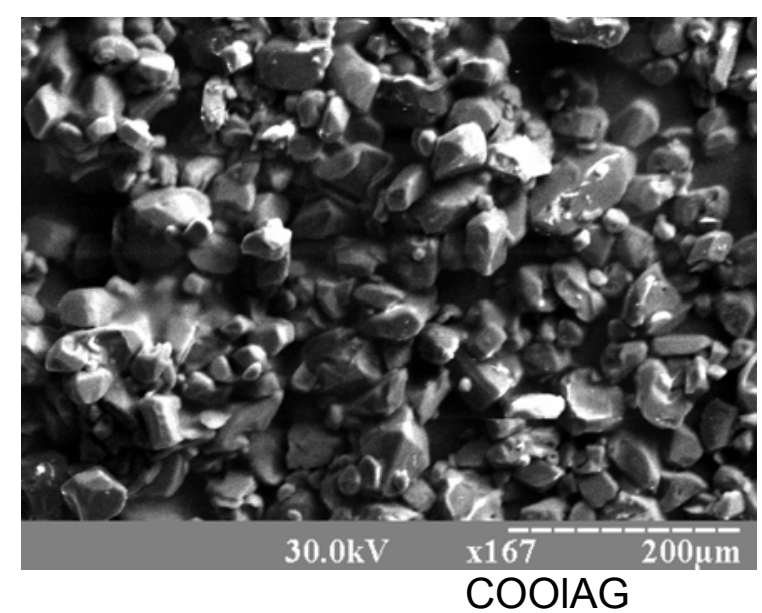

Fig.2. SEM of RDX crystals 


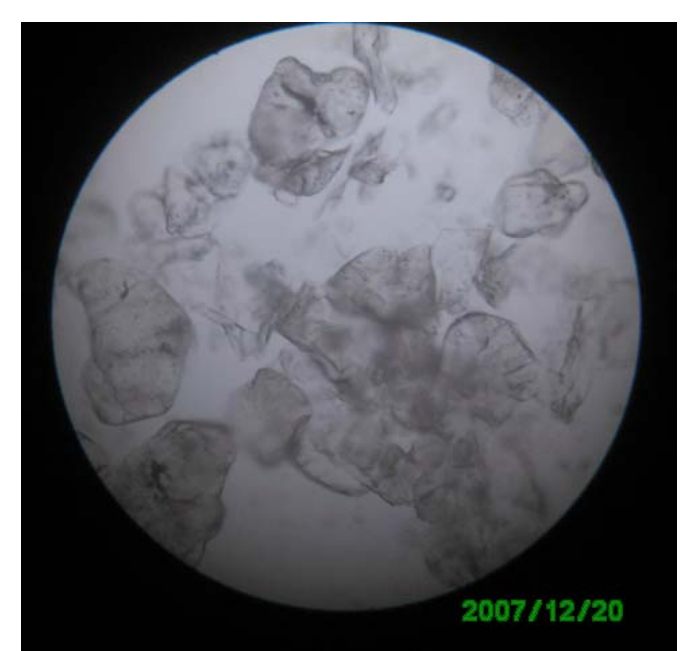

UWAX
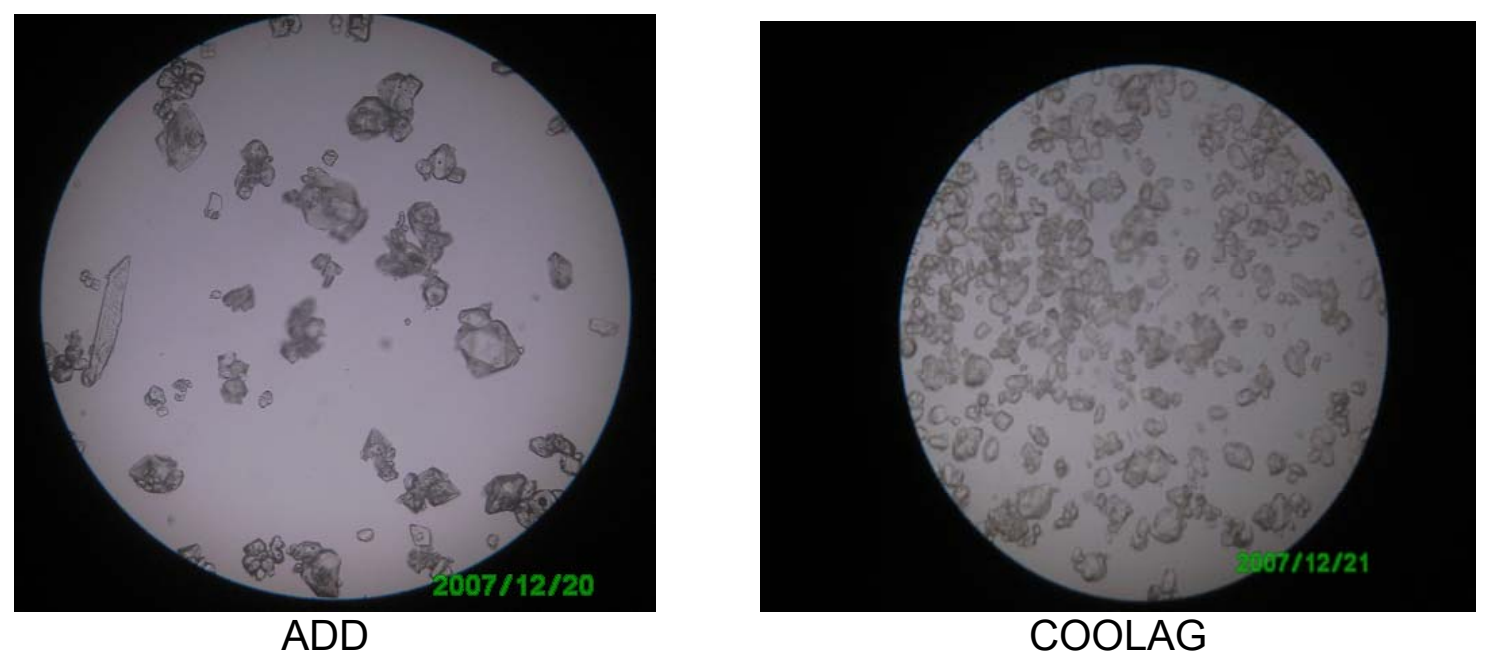

Fig.3. optical microscope of RDX crystals 